\title{
ANALYSIS OF THE IMPLEMENTATION INLISLITE (INTEGRATED LIBRARY SYSTEM)
}

\author{
Pira Yuniar ${ }^{1}$ dan Taufiq Mathar ${ }^{2}$ \\ 1\&2Jurusan Ilmu Perpustakaan, Universitas Islam Negeri Alauddin Makassar \\ Correspondence email: pirayuniar@gmail.com
}

\begin{abstract}
Library automation systems have been widely implemented in various libraries because of its benefits. Dinas Perpustakaan dan Kearsipan (DPK) District of Bantaeng has been using INLISlite since 2015. This descriptive research will describe how the application and the obstacles experienced by the library. The sources of data were obtained through interviews with librarians and library staff who operate INLISlites in the library. The data were analyzed using qualitative data analysis techniques; reduction, display, verification, and conclusion. The results showed that INLISlite has been implemented well even though it still remains significant obstacles. This research can be a reference for other libraries that have implemented a library automation system or integrated library system
\end{abstract}

Keywords: Library automation; integrated library system; INLISlite

\begin{abstract}
Abstrak
Sistem otomasi perpustakaan telah banyak diterapkan di berbagai macam perpustakaan karena manfaatnya yang sangat besar. Dinas Perpustakaan dan Kearsipan (DPK) Kabupaten Bantaeng telah menggunakan INLISlite sejak tahun 2015 lalu. Penelitian deskriptif ini akan menggambarkan bagaimana penerapan dan hambatan yang dialami perpustakaan tersebut. Sumber data diperoleh dari hasil wawancara kepada pustakawan dan staf perpustakaan yang mengoperasikan INLISlite di perpustakaan tersebut. Data dianalisis dengan menggunakan teknik analisis data kualitatif; reduksi, display, verifikasi, dan kesimpulan. Hasil penelitian menunjukkan bahwa INLISlite di perpustakaan ini telah diterapkan dengan baik meskipun tetap menyisakan hambatan-hambatan yang cukup berarti. Penelitian ini dapat menjadi rujukan bagi perpustakaan lainnya yang telah menerapkan sistem otomasi perpustakaan.
\end{abstract}

Kata kunci: Migrasi data; sistem automasi perpustakaan 


\section{Pendahuluan}

Informasi di era saat ini begitu penting (information is powerful). Informasi atau pengetahuan telah menjadi kebutuhan pokok (selain sandang, pangan, dan papan tentunya) bagi semua khalayak. Setiap orang/sekelompok orang dapat memproduksi atau mengemas ulang informasi (information repackage) yang selanjutnya dapat dimanfaatkan dan disebarluaskan dengan begitu cepat dan mudah (Paryati, 2007). Itulah menyebabkan terjadinya banjir informasi (information overload), khususnya dalam format elektronik/digital di dunia maya.

Dalam konteks perpustakaan, di mana perpustakaan telah dikenal sebagai salah satu lembaga atau sarana penyedia informasi mesti membuat "bendungan" agar banjir informasi yang disebutkan di atas dapat dikendalikan dan bahkan dikelola dengan baik. Dengan demikian, masyarakat tidak "hanyut" dalam banjir tersebut, dan bahkan informasi yang mereka butuhkan dapat betul-betul tersaji dengan cepat dan mudah. Tentunya, hal seperti inilah yang mesti dilakukan oleh setiap perpustakaan saat ini.

Tidak dipungkiri, teknologi telah banyak membantu perpustakaan dalam mengelola dan mengorganisir banyaknya informasi yang ada saat ini, baik itu dalam bentuk tercetak maupun elektronik. Salah satu bentuk teknologi tersebut yaitu sistem otomasi perpustakaan atau yang dalam istilah asingnya dikenal dengan integrated library system (ILS). Hadirnya sistem seperti ini, dapat mendukung kinerja sebuah perpustakaan agar dapat lebih meningkatkan layanannya, khususnya dalam hal organisasi pengetahuan (knowledge management) di mana itu merupakan tugas pokok perpustakaan, karena setiap perpustakaan harus berusaha untuk memberikan layanan yang terbaik.

Salah satu sistem otomasi perpustakaan yang ada ialah INLISlite. Sistem otomasi perpustakaan ini dibangun dan dikembangkan oleh Perpustakaan Nasional RI sejak tahun 2011 (Hamid A. , 2015). Sebagaimana sistem otomasi perpustakaan pada umumnya, INLISlite juga berfungsi sebagai sistem tata kelola perpustakaan di mana setiap komponennya terintegrasi antar satu sama lain guna membantu rutinitas pustakawan/tenaga perpustakaan. Sistem otomasi perpustakaan (library automation atau integrated library system) adalah seperangkat aplikasi komputer yang digunakan untuk kegiatan di perpustakaan dengan menggunakan pangkalan data ukuran besar, dan kandungan cantuman tekstual yang dominan, serta dengan fasilitas utama dalam hal menyimpan, menemukan dan menyajikan informasi. (Pendit, 2007). Beberapa definisi lainnya juga disebutkan oleh, di antaranya (CENGAGE, 2020), (elibrary, 2019), (Librarianship Studies \& Information Technology, 2020).

Beberapa perpustakaan di Indonesia telah menggunakan INLISlite sebagai sistem otomasi perpustakaannya, termasuk di DPK Kabupaten Bantaeng, Sulawesi Selatan. Sebelum itu, perpustakaan daerah ini masih menggunakan cara-cara manual di setiap bentuk layanannya. Pada tahun 2012, perpustakaan ini mulai menerapkan sistem pencarian informasi yang berbasis online di mana ketika itu menggunakan sistem yang bernama Sistem Informasi Perpustakaan Online (SIPO) 
dengan maksud agar dapat mempermudah pekerjaan para pustakawan. Akan tetapi sistem ini tidak berjalan lama, karena setahun setelah pemakaiannya sistem tersebut tidak berjalan sesuai dengan ekspektasi perpustakaan. Akhirnya pada tahun 2015, perpustakaan daerah ini menggunakan INLISlite untuk pertama kalinya.

Penelitian ini akan menggambarkan bagaimana penerapan INLISlite di DPK Kabupaten Bantaeng, Sulawesi Selatan serta mendeskripsikan hambatan-hambatan yang dialami dalam penerapannya, baik itu dari sudut pandang pustakawan maupun implikasinya kepada pengguna di perpustakaan ini.

\section{Metodologi}

Penelitian ini merupakan penelitian deskriptif kualitatif yakni penelitian yang berusaha memotret suatu kejadian atau peristiwa pada objek atau pusat perhatiannya. Dalam hal ini ialah INLISlite yang diterapakan di perpustakaan yang dimaksud. Adapun sumber data penelitian ini telah diperoleh melalui wawancara (Sugiyono, 2012) dari pihak perpustakaan itu sendiri, yakni kepala perpustakaan dan juga staf yang ditugaskan mengoperasikan sistem tersebut. Selain itu, observasi (Sarwono, 2006) dan beberapa dokumen pelengkap lainnya seperti dari laporan perpustakaan juga dijadikan data penelitian ini. Data-data tersebut dianalisis dengan teknik analisis data kualitatif (Bryman, 2016), di antaranya dimulai dari mereduksi data-data dengan penggolongan, menentukan arah, hingga "membuang" bagian yang tidak diperlukan. Dari sana, data-data tersebut ditampilkan atau disajikan (display), lalu pada akhirnya diverifikasi untuk ditarik kesimpulan.

\section{Hasil Penelitian}

Sekilas mengenai Kabupaten Bantaeng, di mana secara geografis terletak sekitar $120 \mathrm{~km}$ arah selatan Kota Makassar dengan posisi $5^{0} 21^{\prime} 13^{\prime \prime}$ - 50 35' 26" lintang Selatan dan $119^{\circ}$ 51' 42" - $120^{\circ}$ 05' 27" bujur Timur, posisi wilayah dari tepi Laut Flores sampai ke pegunungan di sekitar Gunung Lompobattang dengan ketinggian wilayah dari permukaan laut 0-25 m sampai dengan ketinggian lebih dari $1.000 \mathrm{~m}$ dari permukaan laut. Kabupaten Bantaeng mempunyai wilayah seluas 395,83 km², di mana secara administratif terdiri atas 8 kecamatan defenitif, 46 desa, dan 21 kelurahan, serta merupakan daerah agraris dengan jumlah penduduk menurut hasil registrasi tahun terakhir sebanyak 178.477 Jiwa. Topografi wilayah Kabupaten Bantaeng yang berbukit di mana seluas 21.69 \% luas wilayah dengan kemiringan lereng lebih $40 \%$ luas wilayah dengan kemiringan 2-15\%. Bantaeng juga tergolong iklim tropis basah dengan curah hujan rata-rata $106 \mathrm{~mm}$ per tahun (Pemerintah Daerah Kabupaten Bantaeng, 2020).

Salah satu layanan publik yang diberikan kabupaten ini ialah DPK. Perpustakaan ini memiliki visi yaitu untuk menjadikan perpustakaan dan kearsipan sebagai pusat saran layanan ilmu pengetahuan dan informasi yang berkualitas. Untuk mendukung terwujudnya visi tersebut, maka salah satu yang perangkat yang disiapkan yaitu sistem otomasi perpustakaan yang digunakan yakni INLISlite. Sistem ini telah digunakan sejak tahun 2015 lalu. 


\section{Penerapan INLISlite}

INLIS singkatan dari Integrated Library System, namun seiring perkembangannya, Perpustakaan Nasional berinisiatif untuk mengembangkan aplikasi tersebut ke dalam versi yang lebih ringan sehingga aplikasi ini berubah menjadi aplikasi INLISlite yang dapat digunakan untuk mempermudah para pustakawan maupun staf perpustakaan di manapun berada, termasuk di DPK Kabupaten Bantaeng.

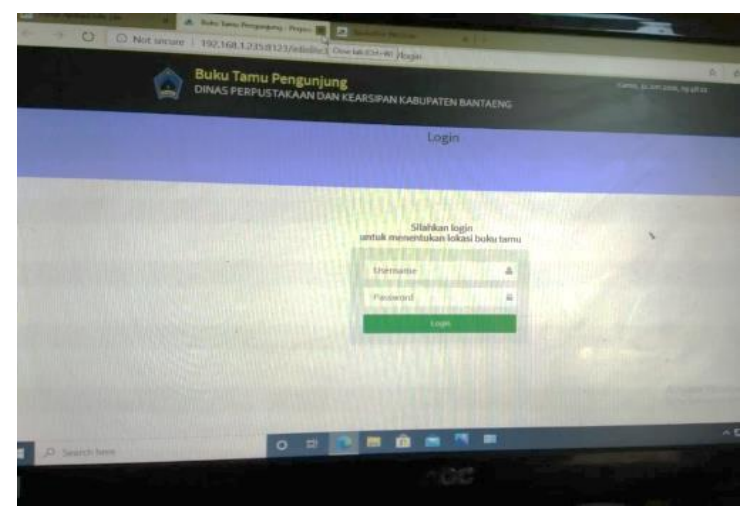

Gambar 1. Laman depan buku tamu yang menggunakan INLISlite di DPK Kab. Bantaeng

Menurut (Suhartika, 2017) INLISlite (Integrated Library System) merupakan aplikasi sistem automasi perpustakaan yang didesain dan dikembangkan oleh perpustakaan Nasional Republik Indonesia pada tahun 2011 yang digunakan untuk membantu proses kegiatan pengelolaan bahan pustaka yang ada di perpustakaan.

'Perpustakaan ini telab lama menggunakan INLISlite sebagai alat (tool) yang digunakan untuk memudahkan kegiatan di perpustakaan. Sistem ini diharapkan mampu menjadi alat yang tepat untuk diterapkan di perpustakaan dikarenakan sistem ini dikembangkan sebagai software oleh Pepustakaan Nasional bagi pengelola perpustakaan ataupun pustakawan untuk. menerapkan sistem otomasi di perpustakaan daerah masing-masing sekaligus bekerja sama mengembangkan, mengelola dan melayankan koleksi digital”, (Suriadi, Hasil wawancara, 2020).

Seiring perkembangannya, saat ini Dinas Perpustakaann dan Kearsipan Daerah Kabupaten Bantaeng telah menerapkan INLISlite versi 3.2. dengan fitur lengkap sehingga semakin memudahkan kegiatan pustakawan dalam mengelola perpustakaan. Aplikasi INLISlite merupakan sistem otomasi yang setiap saat versinya diperbaharui agar menambah kelengkapan fitur. Meskipun sistem otomasi ini sering berubah versi atau sering terjadi pembaharuan sistem, namun hal ini bukanlah suatu hal yang dipermasalahkan, karena semakin sering aplikasi INLISlite diperbahrui justru semakin memudahkan pustakawan dan pengelola perpustakaan dalam melakukan kegiatan di perpustakaan, karena dari sudut pandang teknologi, pembaharuan pada sebuah software itu penting (DesMarais, 2012). 
'Penerapan sistem otomasi INLISlite Versi 3 sangat membantu kinerja pustakawan dan pengelola perpustakaan dalam memaksimalkan pelayanan di perpustakaan, dikarenakan sistem otomasi INLISlite versi 3 memiliki fitur yang beragam sehingga pustakawan dapat menggunakan fitur berbeda sesuai dengan bidangnya masing-masing", (Suriadi, Hasil wawancara, 2020).

Sebagaimana sistem otomasi pada umumnya, INLISlite juga menyediakan beberapa modul yang diperuntukkan untuk perpustakaan, misalnya modul bibliografi atau akuisisi (pengadaan) yang digunakan entri data (biasanya dilakukan oleh bagian pengadaan/pengolahan untuk memasukkan koleksi perpustakaan ke dalam sistem). Gambar di bawah ini yang merupakan modul bibliografi INLISlite DPK Kabupaten Bantaeng. Dengan modul ini, setiap koleksi yang dimiliki perpustakaan dapat didata dan diorganisir lebih baik lagi yang pada akhirnya koleksi-koleksi tersebut dapat diakses oleh para pengguna, khususnya masyarakat Kabupaten Bantaeng.

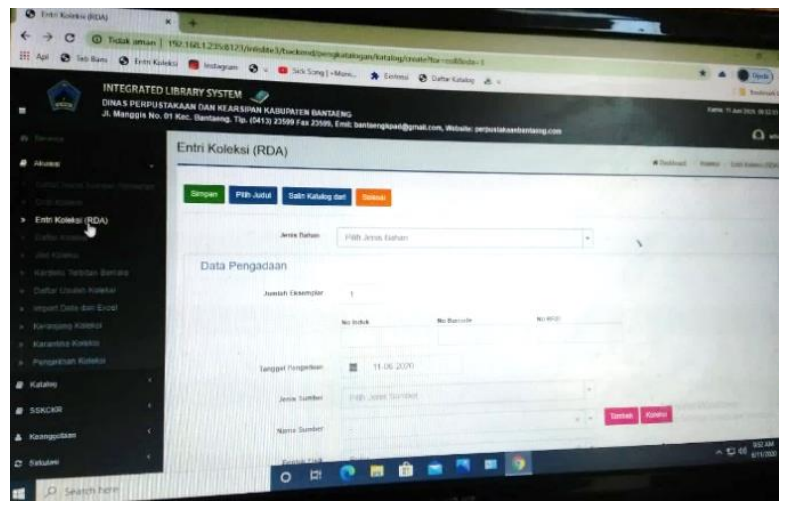

Gambar 1. Modul entri koleksi INSLISlite yang dapat digunakan untuk memasukkan data koleksi perpustakaan

Selain modul bibliografi, pada INLISlite juga terdapat banyak modul-modul lainnya yang karena keterbatasan penelitian ini dari segala aspek, maka tidak dapat mengelaborasi keseluruhan manfaat modul tersebut. Beberapa modul lainnya di antaranya ialah: keanggotaan (membership), katalog online (OPAC), sirkulasi (circulation), laporan (reporting), dan lain sebagainya. Setiap modul tersebut juga terdiri lagi dari sub modul di dalamnya. 


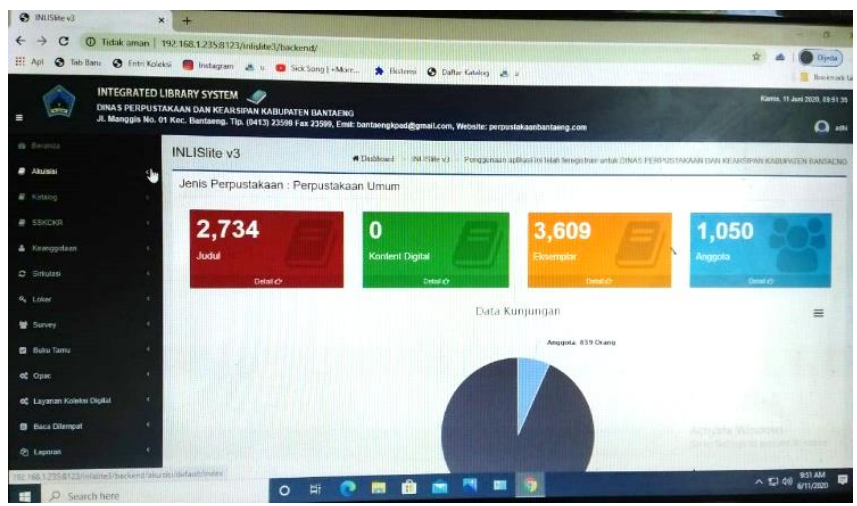

Gambar 2. Laman backend INLISlite yang menampilkan laporan berapa banyak judul, eksemplar, dan sebagainya

Maka inilah yang menjadi mengapa sebuah sistem otomasi perpustakaan itu terintegrasi antar satu sama lain dikarenakan setiap modul memang telah dirancang demikian. Sebagai contoh, sebuah koleksi yang telah di-entry (dimasukkan) oleh pustakawan/tenaga perpustakaan ke dalam sistem melalui modul bibliografi tersebut selanjutnya dapat dilihat pada katalog online (OPAC) dan koleksi tersebut akhirnya dapat dilayankan (dipinjam) oleh para pemustaka dengan memanfaatkan modul sirkulasi (circulation).

Dengan demikian, dalam penerapannya di DPK Kabupaten Bantaeng, INLISlite sejak tahun 2015 lalu telah berjalan dengan baik, meskipun masih menyisakan banyak hambatan dalam proses penerapan tersebut sebagaimana yang akan disebutkan pada hasil penelitian berikutnya.

\section{Hambatan dalam Penerapan INLISlite}

Penerapan sistem otomasi perpustakaan bukanlah suatu kegiatan yang mudah untuk dilakukan karena sering kali pustakawan dan pengelola mengalami hambatan yang pada akhirnya akan berpengaruh pada layanan kepada penggunanya. Pengoperasian sebuah sistem otomasi perpustakaan perlu melibatkan berbagai sumber daya yang ada di perpustakaan agar sistem yang digunakan dapat bekerja sesuai dengan yang diharapkan. Namun demikian, pada kenyataannya banyak sistem yang digunakan tidak dapat beroperasi dengan waktu yang lama dikarenakan tidak atau kurang terkelolanya dengan baik sumber daya yang ada.

Sumber Daya Manusia di DPK Kabupaten Bantaeng menjadi hambatan utama dalam Penerapan INLISlite (Integrated Library System) sebagai sistem otomasi dalam temu balik informasi. Memberikan dukungan teknis serta membiayai kegiatan pelatihan/bimbingan teknis penggunaan sistem dapat menjadi salah satu solusi dalam kecakapan SDM, (Hakim, 2016).

Sebagaimana dinyatakan bahwa "selama penerapan sistem otomasi INLISlite, sebagian pengelola DPK Kabupaten Bantaeng masih kesulitan dalam mengoperasikan teknologi informasi oleh sebagian pengelola. Masib ada sebagian pengelola kurang memahami tentang aplikasi 
INLISlite yang telah diterapkan dikarenakan sebagian pengelola bukan berasal dari jurusan ilmu perpustakaan", (Suriadi, Hasil wawancara, 2020)

Dari sana, "sehingga sering kali terjadi kekeliruan apabila tidak fokus dan teliti dalam penginputan data, misalnya seperti pemberian ISBN buku yang terkadang lupa untuk dimasukkan juga kode Barcodenya sehingga memunculkan masalah di bagian sirkulasi dan pencarian buku di OPAC', (Akbar, Hasil wawancara, 2020)

Meskipun demikian, pengelola perpustakaan tetap berusaha untuk menyesuaikan diri dengan terus belajar dan fokus serta teliti dalam melakukan pengelohan data sehingga informasi yang dilayankan itu jelas dan sesuai dengan ekspektasi para pengguna perpustakaan.

Sementara itu, salah satu hambatan yang dirasakan oleh pemustaka yakni dalam pencarian informasi melalui OPAC pada INLISlite (Integrated Library System) dikarenakan terdapay ketidaksesuain antara call Number yang muncul dilayar tampilan OPAC dengan Call Number yang tertera di rak buku.

Sebagaiman pernyataan salah seorang pemustaka yang menyatakan bahwa Terkadang apa yang ada di OPAC itu tidak ditemukan ketika penelusuran ke rak buku, sehingga membuat pemustaka kebingungan dalam menemukan bahan pustaka yang dibutuhkan. (Linda, 2020)

Sebagian pemustaka lain juga merasakan hambatan pada penerapan INLISlite (Integrated Library System) di DPK Kabupaten Bantaeng. Hambatan yang dirasakan yaitu merasa kebingungan dalam mengoperasikan INLISlite (Integrated Library System). Sehingga pada saat penelusuran informasi sistem otomasi INLISlite (Integrated Library System) tidak dipergunakan karena sebagian pemustaka melakukan penelusuran informasi langsung menuju rak buku.

Seperti yang dikemukakan oleh seorang pemustaka yang menyatakan, dirinya kesuliatan dalam menggunakan fitur-fitur INLISlite (Integrated Library System) yang telah diterapkan di DPK Kabupaten Bantaeng sehingga ketika melakukan pencarian buku, hal yang dilakukan yaitu langsung menuju ke rak buku atau bertanya kepada pustakawan ataupun pengelola perpustakaan letak bahan pustaka yang dibutuhkan. (Wahyuni, 2020)

\section{Pembahasan}

INLISlite telah memberikan banyak perubahan, baik itu dari segi teknis pengelolaan perpustakaan hingga kebijakan-kebijakan yang diambil pimpinan terkait layanan perpustakaan. Dari segi teknis, sistem kerja lebih terarah, terorganisir, dan lebih efisien serta terhubung antar satu sama lain, sebagaimana konsep dari sebuah integrated library system (ILS) atau sistem otomasi perpustakaan. Di lain sisi, kebijakan-kebijakan pun ikut terpengaruhi dengan model kerja yang berbasis IT semacam ini. Tentu yang terakhir disebutkan ini tergantung dari bagaimana pimpinan sebuah perpustakaan mencermati penerapan IT di perpustakaannya. 
Tidak sedikit perpustakaan yang ada saat ini, telah menerapkan sistem otomasi perpustakaan. Hambatan yang paling dirasakan ialah SDM itu sendiri, seperti juga yang dialami oleh pustakawan maupun tenaga perpustakaan di DPK Kabupaten Bantaeng. Namun demikian, dengan adanya keinginan untuk terus belajar dan memahami seluk beluk yang ada pada sistem tersebut, hal-hal yang dulunya dianggap sebagai hambatan kini dapat diselesaikan dengan baik. Hal seperti ini sepatutnya juga dilakukan oleh perpustakaan-perpustakaan yang mengalami hal yang serupa.

Dengan demikian, penerapan sebuah sistem otomasi perpustakaan, yang dalam konteks ini ialah INLISlite di DPK Kabupaten Bantaeng dapat dikatakan telah berjalan sesuai ekspektasi perpustakaan - meskipun pada awal penarapannya mengalami hambatan yang besar, namun seiring dengan berprosesnya waktu semua hambatan tersebut dapat terkelola dengan baik. Ini terbukti bahwa sistem tersebut telah dioperasikan sejak tahun 2015 lalu hingga saat ini tahun 2020, bahkan juga telah melakukan upgrade dari versi lama ke versi baru.

Beberapa catatan penting lainnya ialah, ketika sebuah sistem otomasi perpustakaan hendak diterapkan, orang-orang yang kompeten, termasuk mereka yang memiliki kemampuan IT dapat ikut terlibat. Ini tidak lain agar sistem dapat beroperasi dengan baik. Selain itu, pimpinan juga mesti mengelola dengan baik seluruh sumber daya yang dimiliki perpustakaannya, termasuk SDM yang diberi tugas dalam mengoperasikan sistem otomasi perpustakaan seperti ini, salah satunya dengan selalu memberikan kesempatan kepada SDM-nya untuk belajar ataupun mengikuti training (pelatihan) terkait INLISlite.

\section{Daftar pustaka}

Akbar. (2020, April 10). Hasil wawancara. (P. Yuniar, Interviewer) Bantaeng, Sulawesi Selatan, Indonesia.

Akbar (2020). Hasil Wawancara Staf Ruang Baca Dinas Perpustakaan dan

Kearsipan Daerah Kabupaten Bantaeng [Recorded by Akbar].

Almah, H. (2017). Pemililihan dan Pengembangan: Koleksi Perpustakaan. Makassar:

Alauddin University Press.

Bryman, A. (2016). Social Research Methods. Oxford: Oxford University Press.

CENGAGE. (2020, September 23). Library Automation. Retrieved from

ENCYCLOPEDIA.COM:

https://www.encyclopedia.com/media/encyclopedias-almanacs-

transcripts-and-maps/library-automation

DesMarais, C. (2012, November 20). Why updating your software is a must do.

Retrieved from techlicious.com: https://www.techlicious.com/tip/whyyou-should-update-software-when-prompted/

elibrary. (2019, Mei 6). What is library automation? Retrieved from elibrarysoftware: http://www.elibrarysoftware.com/what-is-library-automation.html

Hakim, A. (2016). Panduan Praktis Pengolahan Bahan Pustaka dengan Program Aplikasi

INLIS Lite Versi 3. Retrieved Juni 24, 2020, from

https://inlislite.perpusnas.go.id 
Hamid, A. (2015). Penerapan INLISlite (Integrated Library System) di Kantor Perpustakaan dan Arsip Daerah Kabupaten Pangkep, Sulawesi Selatan. Khizanah al-Hikmah : Jurnal Ilmu Perpustakaan, Informasi, dan Kearsipan, 112124.

Librarianship Studies \& Information Technology. (2020, Juni 28). Library automation. Retrieved from librarianshipstudies.com: https://www.librarianshipstudies.com/2017/10/library-automation.html Linda, N. (2020). Hasil Wawancara Pemustaka Ruang Baca. Bantaeng, Sulawesi Selatan, Indonesia.

Pemerintah Daerah Kabupaten Bantaeng. (2020, Agustus 10). Kabupaten Bantaeng. Retrieved from Kabupaten Bantaeng: https://bantaengkab.go.id/

Pendit, P. L. (2007). Perpustakaan Digital. Jakarta: Sagung Seto.

Sarwono, J. (2006). Metode Penelitian Kuantitatif dan Kualitatif. Yogyakarta: Graha Ilmu.

Sugiyono. (2012). Metode Penelitian Kuantitatif Kualitatif R \& D. Bandung: Alfabeta.

Suhartika, N. M. (2017). Evaluasi Aplikasi Sistem Automasi Perpustakaan INLIS Lite di Perpustakaan Saraswati Widhyotama Sma Negeri 1 Kuta. Retrieved 11 12, 2019, from file:// /E:/REFERENSI/31852-1357-61926-2-10$20180205 \% 20(1) \cdot p d f$

Suriadi. (2020, April 10). Hasil wawancara. (P. Yuniar, Interviewer) Bantaeng, Sulawesi Selatan, Indonesia.

Wahyuni, R. (2020). Hasil Wawancara Pemustaka Ruang Baca. Bantaeng, Sulawesi Selatan, Indonesia. 